Taking into account current trends in the development of ergatic maritime transport systems, the factors of the navigator's influence on vessel control processes were determined. Within the framework of the research hypothesis, to improve navigation safety, it is necessary to apply predictive data mining models and automated vessel control.

The paper proposes a diagram of the ergatic vessel control system and a model for identifying the influence of the navigator "human factor" during navigation. Within the framework of the model based on the principles of navigator decision trees, prediction by data mining means is applied, taking into account the identifiers of the occurrence of a critical situation. Based on the prediction results, a method for optimal vessel control in critical situations was developed, which is triggered at the nodes of the navigator decision tree, which reduces the likelihood of a critical impact on vessel control.

The proposed approaches were tested in the research laboratory "Development of decision support systems, ergatic and automated vessel control systems". The use of the Navi Trainer 5,000 navigation simulator (Wärtsilä Corporation, Finland) and simulation of the navigation safety control system for critical situations have confirmed its effectiveness. As a result of testing, it was determined that the activation of the system allowed reducing the likelihood of critical situations by $18-54 \%$. In $11 \%$ of cases, the system switched the vessel control processes to automatic mode and, as a result, reduced the risk of emergencies.

The use of automated data mining tools made it possible to neutralize the negative influence of the "human factor" of the navigator and to reduce the average maneuvering time during vessel navigation to $23 \%$

Keywords: vessel control, ergatic system, navigation safety, navigator behavior, accident prediction
UDC UDC 656.61.052

DOI: $10.15587 / 1729-4061.2021 .229237$

\section{NAVIGATION SAFETY CONTROL SYSTEM DEVELOPMENT THROUGH NAVIGATOR ACTION PREDICTION BY DATA MINING MEANS}

Pavlo Nosov $\mathrm{PhD}$, Associate Professor Department of Navigation* Email: pason@ukr.net

Serhii Zinchenko $\mathrm{PhD}$, Associate Professor Department of Ship Handling* E-mail: srz56@ukr.net

Andrii Ben

PhD, Professor, Vice Rector for Research*

E-mail: a_ben@i.ua

Yurii Prokopchuk

Doctor of Technical Sciences, Associate Professor, Leading Researcher Department of System Analysis and Control Problems Institute of Technical Mechanics of National Academy of Sciences of Ukraine Leshko-Popel str. ,15, Dnipro, Ukraine, 49005

E-mail: itk3@ukr.net

Pavlo Mamenko Mediterranean Shipping Company (Cyprus) Ltd. Omonias ave., 57, Strovolos, Cyprus, 2064 E-mail: pavlo.mamenko@gmail.com

Ihor Popovych

Doctor of Psychology, Professor Department of General and Social Psychology

Kherson State University

Universitetskaya str., 27, Kherson, Ukraine, 73003 E-mail: ihorpopovych999@gmail.com VIadyslav Moiseienko Adnoc Logistics \& Services Corniche str., 9, Abu Dhabi, United Arab Emirates E-mail: vladyslavmoiseienko92@gmail.com

DmytroKrugly j

Doctor of Technical Sciences, Associate Professor Department of Innovative Technologies and Technical Means of Navigation* E-mail: psihosovanna@gmail.com

*Kherson State Maritime Academy Ushakova ave., 20, Kherson, Ukraine, 73000

\section{Introduction}

In the practice of managing navigation processes using navigation systems, the initial stage is to draw up a transition plan for a given route [1]. As a rule, the planned route is divided into a number of stages that require additional information from the navigator, as a subject of the ergatic maritime transport system, which allows performing the task with the highest efficiency and safety [2].

However, modern trends in navigation make adjustments leading to the emergence of automated means of remote vessel control, where decisions are made by the operator of navigation information systems (navigator) as a subject of the ergatic maritime transport system [3]. In this context, the navigator is the decision-maker in the full range of navigation situations along the route. In this case, the most important factor for effective decision-making by the navigator is completeness, quality and intensity of incoming navigation information from ECDIS systems and sensors. International maritime and information technology organizations, within their legislative powers, have determined the conditions and requirements for the operation of navigation information systems $[4,5]$.

Autonomous vessels controlled by navigators by means of satellite and coastal communication systems are gradually being put into operation. However, switching to fully autonomous navigation is impossible due to the lack of mathematical 
and logical-algorithmic models of vessel control in critical situations. An effective replacement of the operator-navigator with an artificial control system is required, which will be able to perform navigation tasks with sufficient efficiency. For this replacement, research is needed to analyze the navigator behavior in order to obtain an effective and universal model of vessel control in difficult situations. Thus, the task is to conduct a number of experiments to create a unified series of vessel control models. It should also be taken into account that trends in the development of water transport infrastructure are intensively transformed into specialized centers for managing complex logistics and traffic control systems for sea vessels [6]. This introduces additional requirements both to navigators' qualifications and ability to adequately perceive navigational situations, promptly and efficiently navigate vessels, and make effective management decisions [7]. In these conditions, it is especially important that in a number of studies aimed at analyzing marine accidents, there is a clear pattern from the navigation situation initially identified by the navigator [8]. In real conditions, the identified situation is usually associated with the previous experience of the navigator and directly affects the planning of one's own actions when performing navigation tasks and vessel controls [9]. Consequently, such a state as the "readiness" of the navigator forms the final result of performing tasks, so it requires deeper research and accounting [10]. In turn, the relevance of its definition is directly related to vessel navigation safety. At the same time, navigator's qualification and certification are not questioned, but during critical situations, this does not always guarantee safety. All this necessitates the automated determination of the factors of an unfavorable outcome of critical situations based on implicit features.

\section{Literature review and problem statement}

In [11, 12], the problem of analyzing a large amount of data by the navigator is noted, which significantly increases navigation safety due to the complexity of analyzing the situation in real time. However, the presented approaches are aimed at a formal analysis of linguistic structures based on the knowledge representation model - ontology. These approaches can be most useful in the study of verbal commands and reports during navigational watchkeeping. This limitation does not allow using this theory in full when analyzing captains' direct decision-making and subsequent actions.

In [13], the problems of objective perception of mixed reality by sea cadets in the course of their training for making responsible decisions are indicated.

Also, research is underway aimed at identifying features of navigation situations, which develops data mining systems, and increases the accuracy of decision-making [14].

However, the authors proceed from the principles of cumulative, quantitative assessment of the situation, which in some way may limit the course of the study.

In [15], much attention is paid to the speed of reaction when performing vessel control operations by the navigator. This approach distinguishes this study as innovative and allows approaching the problem of identifying a situation at a qualitatively new level in order to improve navigation safety. However, this work is aimed exclusively at remote object control by the operator and fragmentarily considers the issues related to direct navigator actions.

In turn, the results of modeling in [16] make it possible to quantify the level of attention to the performed operation.
However, this study does not fully disclose the problem of determining the adequacy of situation perception by the navigator relative to the real navigation situation.

Experience of researchers in the field of sports psychology should be taken into account, which also involves the analysis of situation perception by the subject of the system in other activities with high physical and mental loads at the level of borderline capabilities of the human body [17-19]. Much attention is paid to the identification of stressful situations based on observations of a qualified psychologist, but without using automated tools. Despite the importance of the proposed approaches, they cannot be fully applied on vessels, but provide a fragmentary theoretical basis for the processes. A comprehensive analysis of research data indicates the need to create an automated subsystem that will replace the psychologist on board and indirectly indicate stressful situations.

Despite the interest of the scientific community in the problem under consideration, legislative provisions and concepts are little ready for transformations, taking into account the indicated trends [20]. Reduction of the vessel crew, information load and high level of responsibility also introduce factors that directly affect the readiness of navigators to adequately perceive navigational situations.

The problem of the volume and intensity of navigation information in real time has led to the use of intelligent and automated systems that allow for prediction to prevent possible accidents. In [21], an approach to information synchronization is considered for determining instrumental errors in order to improve safety during the navigator's decision-making. However, the solution to the problem of synchronizing not only information data and signals on the captain's bridge, but also actions of the navigational watch, is not sufficiently covered.

Also, in the development of remote vessel control in port areas using satellite navigation, the problem of repetitions by the operators for effective decision-making at a certain stage is revealed [22]. This circumstance indicates the presence of sudden difficulties during the assessment of navigation data. Researchers proposed a methodology aimed at determining memory models of operators to eliminate possible threats of inaccurate situation perception. In conditions of direct control, circumstances associated with bad weather conditions are superimposed, which significantly complicates the navigation control by the navigator $[23,24]$. However, the problem was not fully resolved because a generalized model of navigator's reactions, indicating the occurrence of critical situations was not given. At the same time, weather conditions themselves clearly cannot be an indicator of stress in navigators. In addition, fully automatic control may not be appropriate in all situations, indicating the need for differentiation.

In view of the above, we can conclude that there is an objective problem of identifying critical situations in ergatic vessel control systems, which needs to be solved through the development of innovative approaches to data analysis.

\section{The aim and objectives of the study}

The aim of the study is to develop a navigation safety control system based on navigator action prediction in critical situations, which will reduce the likelihood of critical situations and maneuvering time.

To achieve the aim, the following objectives were set:

- to propose a diagram of the ergatic vessel control system, which will allow determining means of monitoring and 
identifying the situation by the navigator in the process of vessel navigation;

- to develop a generalized model of the influence of the "human factor" on the ergatic navigation systems to determine the signs of critical situations;

- to predict probable critical situations at the nodes of the navigator's decision tree based on hazard identifiers in order to prevent catastrophic consequences;

- to provide emergency switching to the automatic control mode of the vessel when a low probability of a positive result is detected in order to eliminate the negative influence of the "human factor" on the ergatic vessel control system.

\section{Research materials and methods}

A closed process of the ergatic vessel control system is proposed, which concentrates the processes, systems and objects indicated in the tasks. Accurate identification of data and construction of a method for their processing will allow approaching the problem of the negative influence of the "human factor" on the processes of vessel control in critical situations at a qualitatively new level $[25,26]$.

Consider means of monitoring and identifying the situation by the navigator in the process of human-machine interaction with vessel control systems.

Based on the principles of situation recognition set forth in $[27,28]$, navigators in each individual case $Z$ compare the current situation with previous situations that are similar in context to their own experience and established neural connections. In this case, experience is a set of formed atomic reactions $\{G(\tau)\}$, connected by a chain of logical actions: $\alpha(\{0 / T\}) \rightarrow \beta(\{\tau / T\})$. As a rule, there may be several most similar situations to the current one, the similarity of which depends on a whole range of factors and is characterized by the strength of emotional outburst identified using pulse and saturation sensors.

Depending on the degree of similarity, a logical connection arises between the current situation $\beta$ and the most similar one in context and degree from the past experience $\alpha$ (Fig. 1). Then the comparison of the two most similar situations is defined as

$$
\operatorname{Sim}(\alpha, \beta \mid\{\tau / T\})=\left|\{\underline{\tau} / T\}_{\alpha} \cap\{\underline{\tau} / T\}_{\beta}\right| /|\{\tau\}|,
$$

where $\underline{\tau}$ is the terminal element of experience with respect to the performed operation.

It should also be taken into account that the lower the threshold of the emotional outburst of the situation $\beta$, the more difficult it is to identify the similarity with the situation $\alpha$, since:

$$
\begin{aligned}
& \forall \alpha, \beta \text { if }\{\tau / T\} \leq\left\{\tau / T^{\prime}\right\} \Rightarrow \\
& \Rightarrow 0 \leq \operatorname{Sim}(\alpha, \beta \mid\{\tau / T\}) \leq \operatorname{Sim}\left(\alpha, \beta \mid\left\{\tau / T^{\prime}\right\}\right) \leq 1
\end{aligned}
$$

Of course, depending on the completeness of $\{G(\tau)\}$, it becomes possible to determine the maximum similarity of $\alpha$ and $\beta$ :

$$
\operatorname{Sim}(\alpha, \beta \mid\{G(\tau)\})=\max _{\{\tau / T\}^{\wedge}} \operatorname{Sim}(\alpha, \beta \mid\{\tau / T\})
$$$$
M=\prod_{\tau \in\{\tau\}}|[G(\tau)]|
$$

where $M$ is the number of similarities, and $\{\tau / T\}^{\wedge}$ is the set of terminal domains.

Thus, the likelihood of an increase in the risk of maritime disasters arises due to the absence of the factor of "distinguishing" between the two situations, $\{\tau / T\}_{\alpha} \approx\{\tau / T\}_{\beta}$. The only possible distinguishing feature is the context of the situation with similar emotional outbursts:

$$
K^{e m}=\langle\Omega(Z),\{G(\tau)\},\{S\}\rangle,
$$

then:

$$
\begin{aligned}
& \operatorname{Con}\left(\alpha, \beta \mid K^{e m}\right)=1 \Leftrightarrow z_{\alpha}=z_{\beta}, \\
& \text { else } \operatorname{Con}\left(\alpha, \beta \mid K^{e m}\right)<1
\end{aligned}
$$

where $S$ is the formed experienced reactions.

At the same time, an important element of analyzing the situation context is the ability to deeply identify and process incoming signals from sensors [29, 30]. In turn, the navigator's identification ability depends on the sequential concentration of attention on several information sources, which can be expressed in the form of $p$-adic structures [31]. Suppose that the current state of identification $I$ is expressed by a set of values $x$ relative to the active sources of navigation information $B$ of the form:

$$
x=\alpha_{0}+p+\ldots+\alpha_{n-1} p^{n-1} .
$$

In this case, there may be situations when different forms of their perception by means of $p$-adicity can be combined into a single system by converting coding forms. This can may the case when several devices with different levels of detail are involved for a certain fragment of the problem.

Then the value of $p$-adicity, which characterizes the situation complexity, is formed by the rightmost element of expression $\alpha_{n-1} p^{n-1}$.

It should be noted that the concentration of the navigator's attention is maximum at $\alpha_{0}$ and weakens at $\alpha_{i+1, \ldots, m}$, which indicates the priority of the element.

Thus, when performing the navigation task, two critical parameters can be determined. The first parameter: "maximum coverage-identification" of the current situation. This parameter describes the process of covering the primary signal by the navigator (in the accepted $p$-adicity). The further the navigator goes along the chain of events, the more data it operates with, the deeper the identification (Fig. 1).

So, Fig. 2 shows that the situation of such a task as "Analysis of navigation hazards on the route" is fragmented into four stages. ECDIS (Electronic Chart Display \& Information System) acts as a source of navigation information, which may have different $p$-adicity at certain stages. The analysis of this situation indicates an increase in the complexity of its perception by the navigator, since $p$-adicity increases with each subsequent stage and keeps physiological indicators of stress at a high level.

The second parameter: recorded "emotional outburst". Let's consider a formal description of this parameter. Suppose that each identified "emotional outburst" is nothing more than an attractor $\alpha_{j}^{(n)}$, then the formation of the trajectory of actions starting from the first fragment will be carried out according to the principle $x_{0} \in U_{1 / p}\left(\alpha_{j}^{(n)}\right)$. In a real experiment, such a situation will initially have increased emotional and physiological indicators (pulse and saturation), regardless of the degree of $p$-adicity of the trajectory stages: 


$$
\alpha_{j}^{(n)}=h_{0}^{j}+h_{1}^{j} p+\ldots+h_{n-1}^{j} p^{n-1},(s, p) \neq 1 .
$$
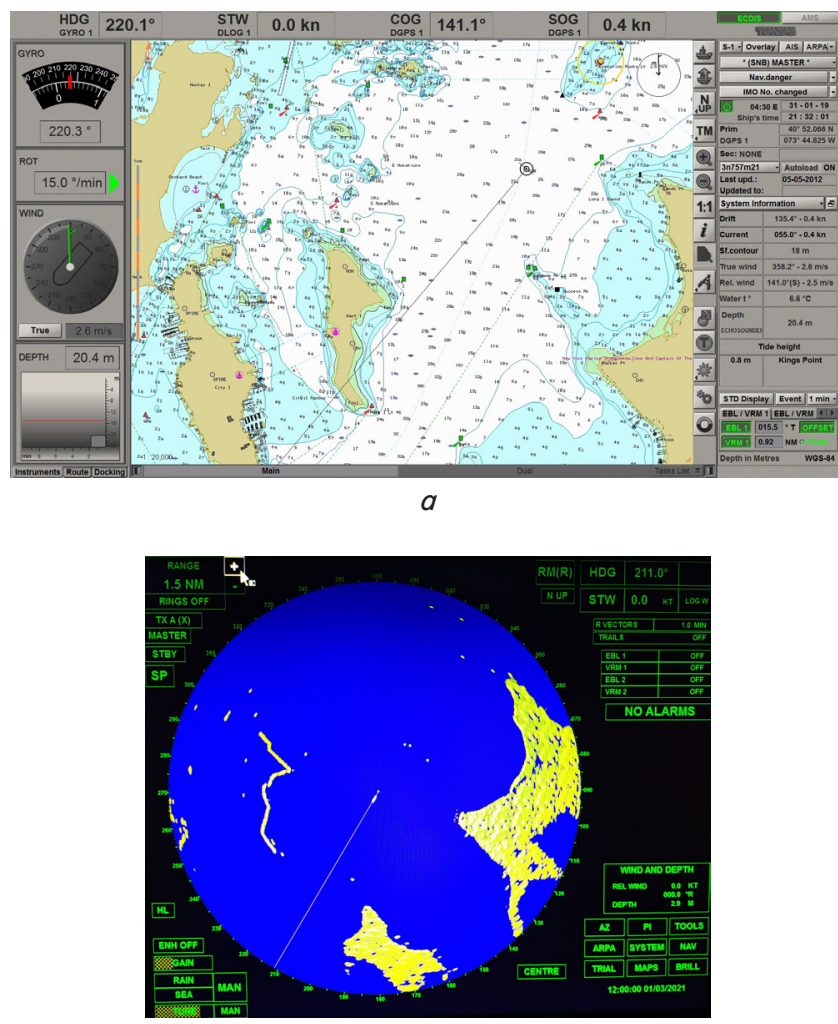

$b$

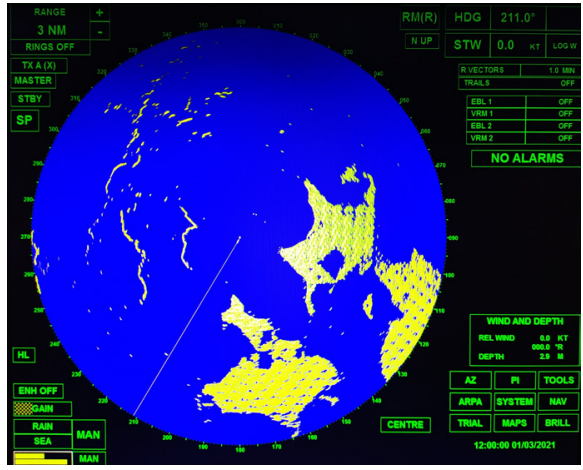

c

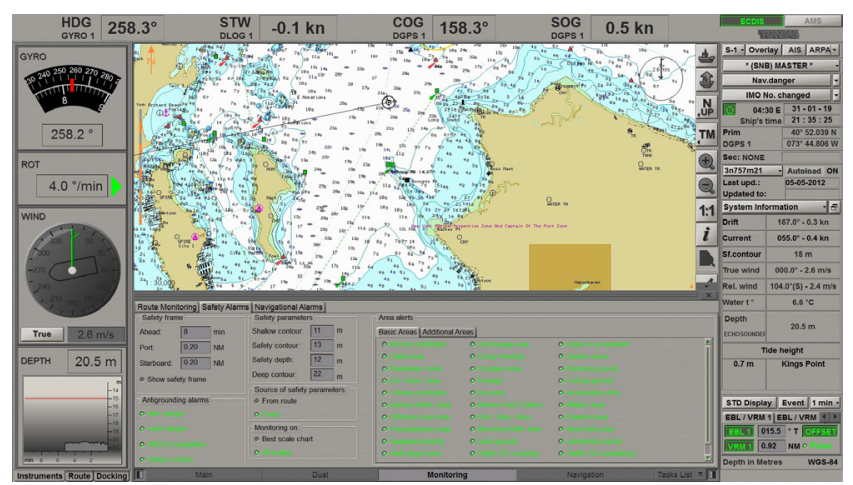

d

Fig. 1. Complexity of the situation: $a-$ identification $p_{t 1}=3$;

$b$ - identification $p_{t 2}=4 ; c-$ identification $p_{t 3}=5$; $d-$ identification $p_{t 4}=7$
However, such a feature was noted that an unfamiliar situation increases the level of emotional outburst throughout the entire task, which confirms the presence of an attractor $\alpha_{j}^{(n)}$ in the situation $B_{i}$.

The second point is most important when there is a sharp "emotional outburst" at the stage $h_{\tau^{e m}}^{j}$, where $v_{t_{i}}^{e m}>\max \Delta v^{e m}$, where $\Delta v^{e m}$ is taken as the average individual pulse/saturation value to perform the operation effectively. This factor directly increases the complexity of the current stage $h_{\tau^{e m}}^{j}$, the trajectory of navigator's actions.

Then, for example, if at the stage $\alpha_{1}$ there was an "emotional outburst" above the average strength $\alpha_{1}=2$, then the influence of "emotional outburst" of strength $\alpha_{j}^{(n)}=2$. will be distributed to the subsequent ones $\alpha_{j}^{(n)}$, where $j=2,3 \ldots$. In this case, the trajectory of navigator's actions can be represented as an algorithm $\{A\}$ relative to the objects of the location $V_{1}, \ldots, V_{m}$ in the form of $S_{1}(A), \ldots, S_{m}(A)$.

The algorithms of navigator's behavior with respect to $V_{1}, \ldots, V_{m}$ are identified as factors affecting the complex of vessel technical systems. In addition, $\forall\{A\}$ is determined by a set of numerical control parameters of the ergatic system, $\pi_{1}, \ldots, \pi_{\mathrm{q}}$. Then: $S_{1}(A)=S_{1}\left(\pi_{1}, \ldots, \pi_{q}\right), \ldots, S_{m}(A)=S_{m}\left(\pi_{1}, \ldots, \pi_{q}\right)$. During the study, it is important to determine the context of the situation accompanied by "emotional outburst" in relation to the performed task.

Trends in the influence of navigators' actions on the efficiency of ergatic vessel control systems were determined during the analysis of formal concepts [28]. Taking into account the complexity of identifying the influence of navigators on the efficiency of ergatic vessel control systems, a model was built based on analyzing the behavior of each vessel watch navigator. At the same time, the indicator of their emotional outburst in relation to the indicated stages of the captain's actions algorithm was taken into account. This approach made it possible to increase the reliability of identifying violations or failures in the course of collective actions.

Thus, the initial task was to synchronize experimental results with respect to the identified trajectory of all watch members' attention. This made it possible, taking into account the navigation situation, to predetermine the trajectories of watch members' attention with a sufficiently high accuracy based on the central trajectory of the captain's attention. Synchronization of watch actions can be identified based on the context $K=\left(G, M^{*}, I\right)$, where $G$ is an integral indicator of the parameters of the ECDIS, ARPA, AIS systems.

The coincidence of atomic actions $\Omega$ in the trajectory chain implies the formation of indirect signs $M^{*}$ such that $I \subset G \times M^{*}$, where $I$ is the set of imaginary coincidences of situations on the route trajectory. Taking into account that an important prerequisite for forming the trajectory of perception of the navigation situation is the initially formed experimental connections $\underline{\tau} / T_{0}$ of navigators, $\Omega=\left\{\alpha\left(\underline{\tau} / T_{0}\right)\right\}$.

The coincidence criterion is presented as the context

$$
K_{\{\tau / T\}}^{\text {coll }}=\left(\Omega,\{G(\tau)\}, I_{\{\tau / T\}}\right) \Rightarrow I_{\{\tau / T\}} \subseteq \Omega \times M_{\{\tau / T\}}^{*} .
$$

In turn, $K_{\{\mathrm{r} / T\}}^{\text {coll }}$, determines the degree of compliance of the situation with respect to the collective perception of a group of elements of the ergatic system - navigational watch. In this case, $K_{\{z T\}}^{\text {coll }}$ also relies on the formed collective prerequisites (predispositions) of perception relative to the current navigation task $Z$, obtained as a result of analyzing many previous decisions with a positive effect, such that $\Omega^{\text {coll }}(Z)=\left\{\alpha\left(\{S\}_{\alpha}, \underline{z} / Z\right)\right\}$. This changes the structure of the context $K_{\{\tau / T\}}^{\text {coll }}$ and forms the 
attitude of the team's disposition to the situation. As a result of analyzing the behavior of each member of the navigational watch, it becomes possible to identify conceptual limitations in the perception of the current situation by the watch. At the same time, the boundaries of the influence of the context $K_{s, c \text { coll }}$ on the identification of the situation by the members of the navigational watch are determined. So, for example, based on the experience of two navigators, A and B, regarding a typical situation, but in different locations (ports), a corresponding feature space is formed, such that:

$$
A^{\prime}\left(B^{\prime}\right)=\{m(g) \in M(G) \mid \forall g(m) \in A(B)(g I m)\} .
$$

At the same time, it is important to assess to what extent these feature spaces of navigation situation perception by different navigators in the watch were close.

It is logical to assume that the atomic actions of navigators $\{\alpha\} \subseteq \Omega$ when performing the task $\underline{Z}$ produced the properties of correspondence of the current situation with respect to the context $K_{\{b / B\} \cup\{a / A\}}$ :

$$
\left.\{\alpha\}^{\prime}\right|_{\{\tau / T\}}=\left\{\underline{b} / B \in M_{\{\tau / T\}} \mid \forall \alpha \in\{\alpha\}\left(\alpha I_{\{\tau / T\}} \underline{b} / B\right)\right\} .
$$

Consequently, the higher the influence of the context, and also the closer the trajectory of attention of watch crew members to the captain's strategy, the higher the efficiency of the ergatic vessel control system.

It became possible to determine trajectories that differ from the expected ones, especially in situations where the level of $p$-adicity is high enough and corresponds to the required depth of temporal identification of the navigation situation $I_{\{S\}}^{t}$, such that:

$$
\begin{aligned}
& \left.\{\alpha\}^{\prime}\right|_{\{S\}}=\left\{S \in\{S\} \mid \forall \alpha \in\{\alpha\}\left(\alpha I_{\{S\}}^{t} S\right)\right\} \Rightarrow \\
& \left.\Rightarrow\left\{S_{i}\right\}^{\prime}\right|_{\{S\}}=\left\{\alpha \in \Omega \mid \forall S \in\left\{S_{i}\right\}\left(\alpha I_{\{S\}}^{t} S\right)\right\} .
\end{aligned}
$$



$a$

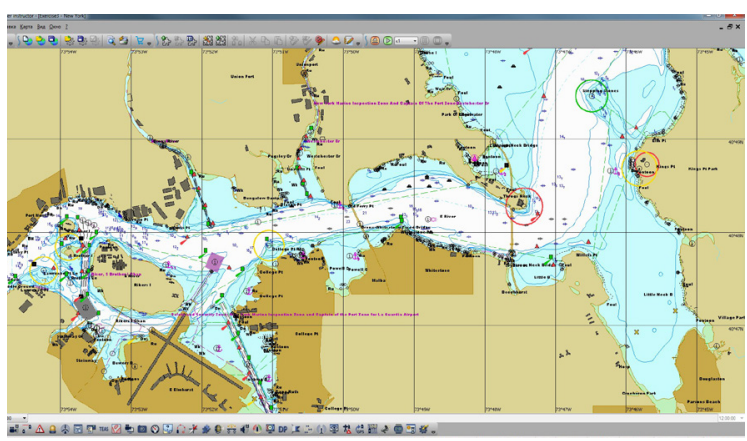

$c$
In such situations, the automated system monitored the activity of the subjects of the ergatic system and activated the module for analyzing physiological parameters in order to determine the presence of "emotional outbursts" during the passage of fragments of a given route.

Thus, for eachtypicalsituation, thezone $\{S\}_{\Omega j}^{t_{j \ldots n}}=\cap_{\alpha \in \Omega j}\{S\}_{\alpha}$, $j \in Z$, of similar temporal features of formal description of the current situation appeared. The sets formed in this way determine the area of navigator interaction with the objects and subjects of the ergatic system in a given range:

$$
\{S\}_{j}^{\perp}=\{S\}_{j} \backslash\{S\}_{\Omega j}^{t_{j \ldots n}}, \quad\{S\}_{\Omega j}^{t_{j \ldots n}}=\varnothing .
$$

Thus, it became possible to determine those features that are not included in the zone of similar ones and are identified by the navigator as an "unrecognizable" situation. The determinant of the emergence of such an "unrecognizable" situation in the algorithm chain was a persistent "emotional outburst", a constant level of emotional stress. An indicator of situation complexity was an increased and non-fading pulse and decreased saturation $\{R\}$. Comparing the time indices of the navigator's reactions in the zone of "emotional outburst" $t *$ with the time indices of the previous stable state, it is possible to determine how much the situation does not correspond to initial expectations:

$$
K_{\{R\}}^{t^{*}}=\left(\Omega(Z),\left\{R^{t^{t}}\right\}, I_{\{R\}}\right), I_{\{R\}} \subseteq \Omega \times\left\{R^{t^{*}}\right\},
$$

where

$$
t^{*}>\max \Delta t_{\{\mathrm{S} \alpha(\beta)\}} \text {. }
$$

To confirm the adequacy of the proposed approach, the Navi Trainer 5000 navigation simulator (NTPRO 5000) was used (Fig. 2).
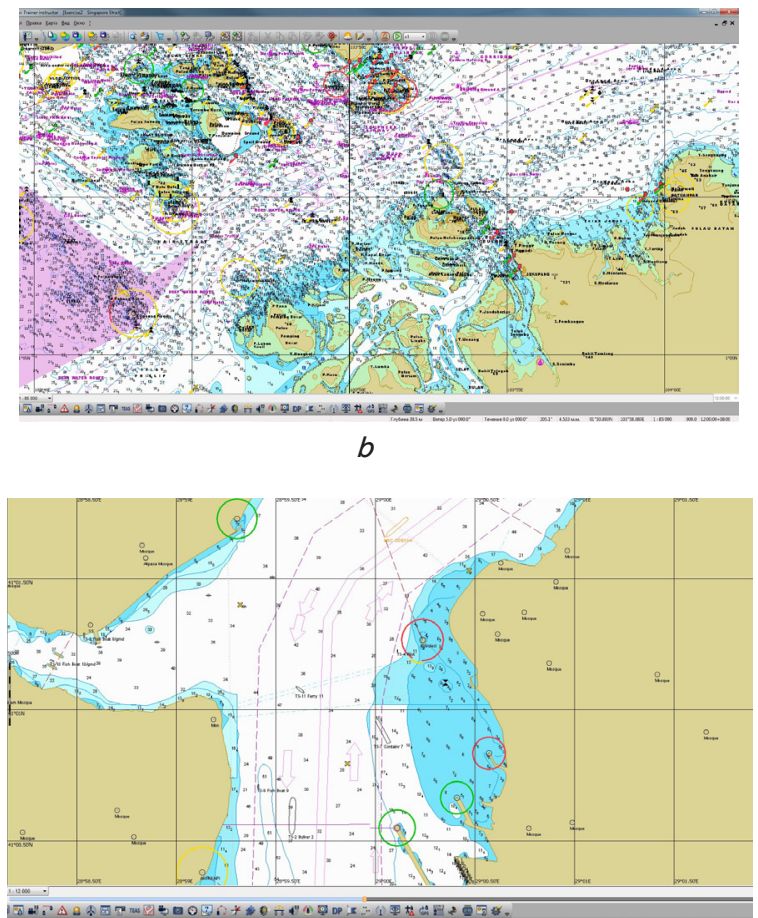

$d$

Fig. 2. Locations used for modeling in NTPRO 5000: $a$ - Hong Kong Strait (HK); $b-$ Singapore Strait (Sp); $c$ - East River, USA (NY); $d$ - Bosphorus Strait, Turkey (BT) 
The proposed approaches were tested in the research laboratory "Development of decision support systems, ergatic and automated vessel control systems". In the process of testing, to confirm the adequacy of the developed model, a closed-circuit simulation of control processes with a mathematical model of the vessel was carried out on the simulation stand in critical situations of the selected locations.

5. Results of simulation of navigation safety control processes using NTPRO 5000 in the Bosphorus location

5. 1. Development of a diagram of the ergatic vessel control system

A diagram of the ergatic vessel control system was developed. Within the framework of the proposed diagram of the ergatic vessel control system, approaches to data extraction based on the results of analyzing navigation processes in critical situations were determined. Connections between the structural elements of the diagram in the form of logical and algorithmic dependencies were determined (Fig. 3).

The formal description of the links allowed determining the range of the concepts of complex formalization of navigators' actions. This approach made it possible to algorithmize the means of monitoring and identifying the situation in the process of vessel control.
5. 2. Development of a generalized model of the influence of the "human factor"

Having identified the main significant factors affecting the ergatic navigation system, it became possible to build a generalized model of the influence of the "human factor" on ergatic navigation systems for critical situations (Fig. 4).

According to the proposed model, we define a group of factors that identify the situation for the navigator (Table 1) and factors influencing the occurrence of risk (Table 2).

Table 1

Factors determining the situation for the subject of the ergatic vessel control system

\begin{tabular}{|c|c|c|c|}
\hline No. & Factor & Factor determination process & Parameters \\
\hline Fs1 & Danger of vessel movement & $\begin{array}{c}\text { Vessel speed (relative to maximum) near } \\
\text { hazardous objects (ECDIS data) }\end{array}$ & $0 \ldots 1$ max \\
\hline Fs2 & $\begin{array}{c}\text { Determination of similarity } \\
\text { completeness }\end{array}$ & $\begin{array}{c}\text { Similarity in flow rate, date and time of } \\
\text { day, vessel type }\end{array}$ & $0 \ldots 1$ \\
\hline Fs3 & $\begin{array}{c}\text { Risk of indistinguishable } \\
\text { situations }\end{array}$ & $\begin{array}{c}\text { Determination of significant differences } \\
\text { between two similar situations by exter- } \\
\text { nal weather factors }\end{array}$ & $>10 \%$ \\
\hline Fs4 & $\begin{array}{c}\text { Analysis of "emotional } \\
\text { outburst" }\end{array}$ & $\begin{array}{c}\text { Coincidence of emotional outburst near } \\
\text { the vessel's waypoint }\end{array}$ & $0.2 \ldots 0.5 \mathrm{~nm}$ \\
\hline Fs5 & $\begin{array}{c}\text { Analysis of navigator's } \\
\text { heart rate/saturation }\end{array}$ & $\begin{array}{c}\text { Determination of maximum pulse } \\
\text { extremes and minimum blood saturation } \\
\text { extremes }\end{array}$ & $>135 \mathrm{bpm}$ \\
\hline Fs6 & $\begin{array}{c}\text { Analysis of the complexity } \\
\text { of the p-adicity situation of } \\
\text { the stage }\end{array}$ & $\begin{array}{c}\text { Determination of transitions to the } \\
\text { ECDIS, ARPA, AIS, GPS interfaces, } \\
\text { operating with many information factors } \\
\text { and signals }\end{array}$ & $p=3 \ldots n$ \\
\hline Fs7 & $\begin{array}{c}\text { Analysis of the impact on } \\
\text { the ergatic system }\end{array}$ & $\begin{array}{c}\text { Degree of danger of current operating } \\
\text { modes for objects of the ergatic system }\end{array}$ & $0 \ldots 1$ \\
\hline Fs8 & $\begin{array}{c}\text { Behavior analysis based on } \\
\text { the experience of actions }\end{array}$ & $\begin{array}{c}\text { Coincidence of the chains of current navi- } \\
\text { gators' actions with respect to established } \\
\text { experienced reactions }\end{array}$ & $>85 \%$ \\
\hline Fs9 & $\begin{array}{c}\text { Synchronization with } \\
\text { the team }\end{array}$ & $\begin{array}{c}\text { Coincidence of the chains of current } \\
\text { actions of the navigational watch relative } \\
\text { to experienced reactions }\end{array}$ & $>70 \%$ \\
\hline
\end{tabular}

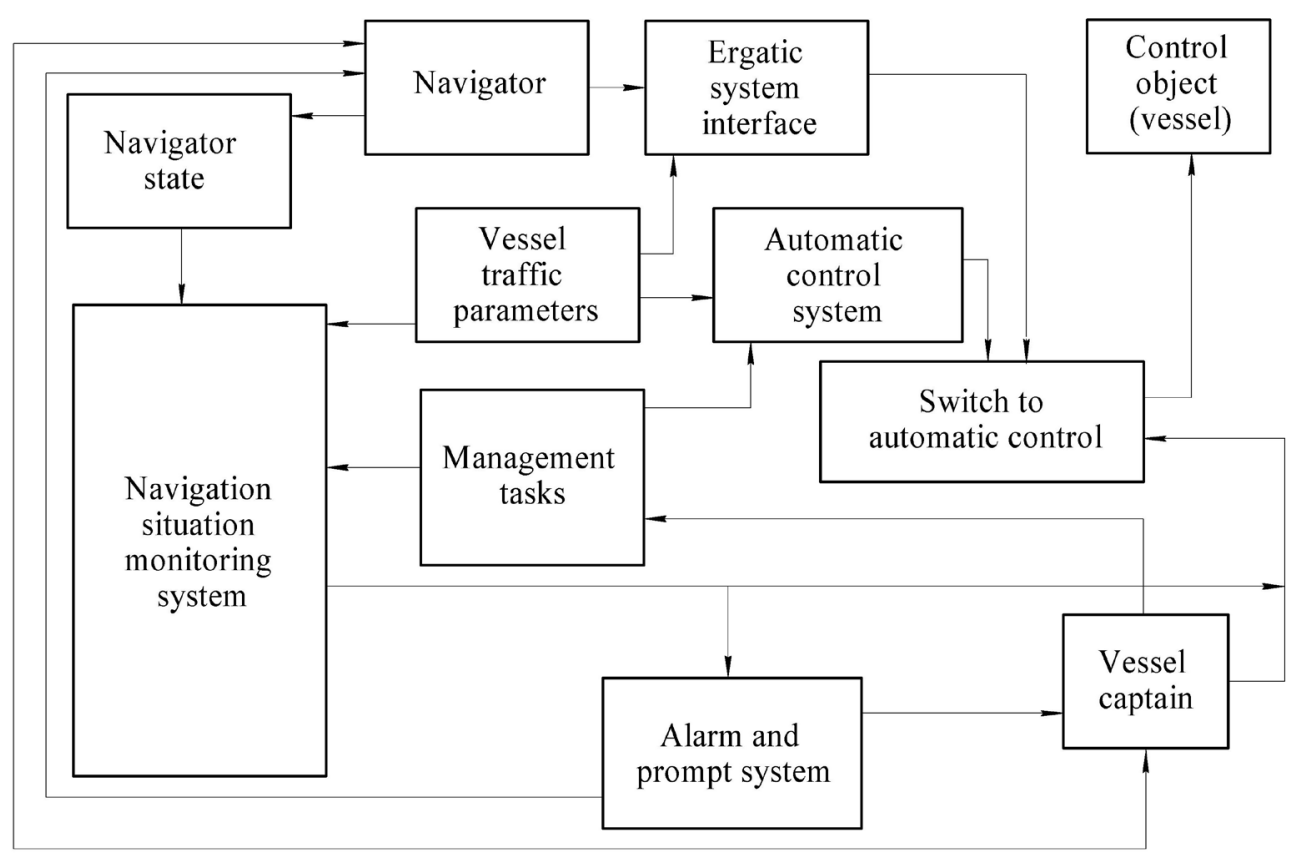

Fig. 3. Diagram of the ergatic vessel control system 


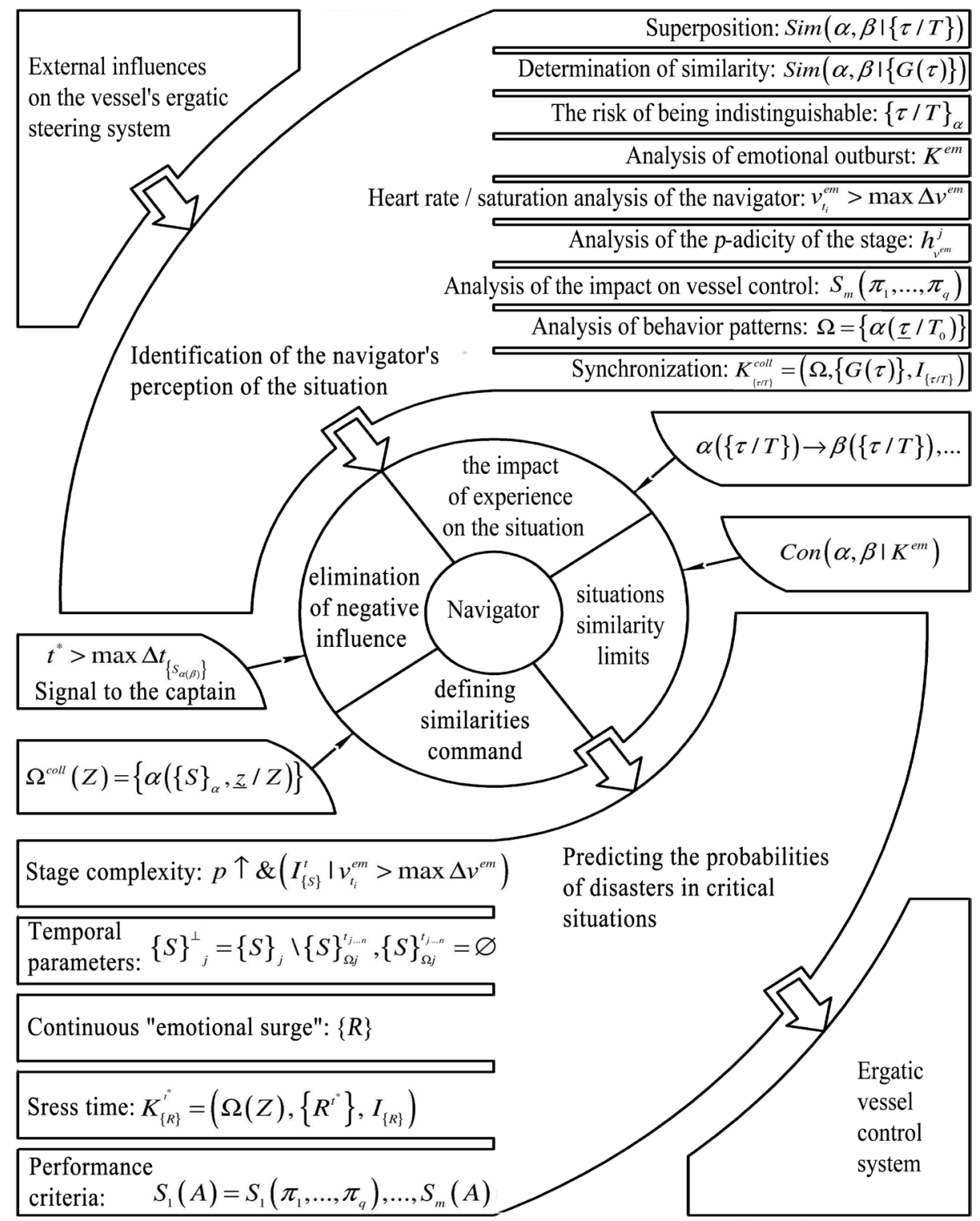

Fig. 4. Generalized model of the influence of the "human factor" on ergatic navigation systems

Table 2 Thus, it becomes possible to simulate the

Factors influencing the occurrence of risk in the current situation

\begin{tabular}{|c|c|c|c|}
\hline No. & Factor & Factor determination process & Parameters \\
\hline Fr1 & $\begin{array}{l}\text { Determining the situation } \\
\text { complexity }\end{array}$ & $\begin{array}{c}\text { Sharply increasing } p \text {-adicity } \\
\text { of the stage }\end{array}$ & $p_{i+m},(m>2)$ \\
\hline Fr2 & Temporal parameters & $\begin{array}{c}\text { Similarity of time ranges } \\
\text { of operations performed by } \\
\text { navigators }\end{array}$ & $0 \ldots 1$ \\
\hline Fr3 & $\begin{array}{l}\text { Determinant of the emer- } \\
\text { gence of an "unrecogniza- } \\
\text { ble situation", continuous } \\
\text { emotional outburst }\end{array}$ & $\begin{array}{l}\text { Determination of high heart } \\
\text { rate and oxygen saturation, } \\
\text { exceeding the average values } \\
\text { for the whole team }\end{array}$ & $>30 \%$ \\
\hline Fr4 & $\begin{array}{l}\text { Comparison of time indi- } \\
\text { cators of stress }\end{array}$ & $\begin{array}{c}\text { Determination of long-term } \\
\text { deviations of heart rate and } \\
\text { saturation }\end{array}$ & $>1.4 \Delta t$ \\
\hline Fr5 & $\begin{array}{l}\text { Criteria for the effectivef } \\
\text { ness of task performance } \\
\text { by the navigator }\end{array}$ & $\begin{array}{c}\text { Using data mining technoloa } \\
\text { gy to build task performance } \\
\text { trees based on influencing } \\
\text { factors }\end{array}$ & $\begin{array}{l}\text { successful/ } \\
\text { unsuccessful }\end{array}$ \\
\hline
\end{tabular}
generalized control life cycle, in particular, the process of vessel movement in ergatic systems, using the example of four locations: the Hong Kong Strait, the Singapore Strait, the East River (New York), and the Bosphorus Strait.

During the analysis, it was determined that the basic factors of the locations are sufficiently similar. This allows summarizing the data to determine the patterns (Table 3 ).

It should be borne in mind that the factors Fs1-9 and Fr1-5 are presented in the following parameter ranges: Fs1 (0.1...0.5 nm); Fs2 (0..1); Fs3 (>10\%); Fs4 (0.2...0.5 nm); Fs5 (>135 bpm, $96 \%<$ saturation); Fs6 $(p=3 \ldots n)$; Fs7 (0...1); Fs8 $(>85 \%)$; Fs9 $(>70 \%)$; Fr1 $\left(p_{i+m},(m>2)\right.$; Fr2 $(0 \ldots 1) ; \operatorname{Fr} 3(>30 \%)$; Fr4 (>1.4 $\Delta t)$; Fr5 (successful/unsuccessful).

To construct decision trees by the automated data mining method, the CART algorithm is used, in which the Gini index acts as an accuracy criterion [32]. 
Table 3

Simulation results of the navigation simulator

\begin{tabular}{|c|c|c|c|c|c|c|c|c|c|c|c|c|c|c|}
\hline Location code & Fs1 & Fs2 & Fs3 & Fs4 & Fs5 & Fs6 & Fs7 & Fs8 & Fs9 & Fr1 & Fr2 & Fr3 & Fr4 & Fr5 \\
\hline HK1 & 0.2 & 0.9 & 1 & 0.3 & 1 & 6 & 0.4 & 1 & 0 & 1 & 0.8 & 0 & 1 & Yes \\
\hline Sp1 & 0.3 & 0.8 & 1 & 0.2 & 0 & 4 & 0.3 & 1 & 0 & 0 & 0.8 & 0 & 0 & Yes \\
\hline NY1 & 0.1 & 1 & 1 & 0.2 & 0 & 5 & 0.1 & 0 & 1 & 0 & 0.7 & 0 & 1 & Yes \\
\hline BT1 & 0.1 & 0.8 & 0 & 0.5 & 1 & 6 & 0.5 & 0 & 0 & 1 & 0.3 & 1 & 1 & Yes \\
\hline HK2 & 0.3 & 0.8 & 0 & 0.3 & 0 & 3 & 0.3 & 1 & 0 & 0 & 0.8 & 0 & 0 & Yes \\
\hline Sp2 & 0.3 & 1 & 0 & 0.3 & 0 & 5 & 0.3 & 1 & 0 & 0 & 0.9 & 0 & 0 & Yes \\
\hline NY2 & 0.2 & 0.9 & 0 & 0.2 & 1 & 4 & 0.2 & 1 & 1 & 0 & 0.8 & 0 & 0 & Yes \\
\hline BT2 & 0.1 & 0.8 & 0 & 0.5 & 1 & 7 & 0.6 & 0 & 0 & 1 & 0.7 & 1 & 1 & Yes \\
\hline HK3 & 0.2 & 0.9 & 1 & 0.2 & 0 & 4 & 0.4 & 1 & 0 & 0 & 0.9 & 0 & 0 & No \\
\hline Sp3 & 0.3 & 0.7 & 1 & 0.4 & 0 & 7 & 0.6 & 0 & 1 & 0 & 0.1 & 1 & 1 & Yes \\
\hline NY3 & 0.2 & 1 & 1 & 0.3 & 0 & 4 & 0.3 & 1 & 1 & 1 & 0.8 & 0 & 0 & Yes \\
\hline ВT3 & 0.2 & 0.8 & 0 & 0.4 & 0 & 5 & 0.3 & 0 & 0 & 0 & 0.7 & 1 & 1 & Yes \\
\hline HK4 & 0.3 & 1 & 0 & 0.4 & 0 & 6 & 0.4 & 1 & 0 & 0 & 0.6 & 1 & 1 & Yes \\
\hline Sp4 & 0.4 & 0.8 & 0 & 0.3 & 1 & 4 & 0.3 & 1 & 1 & 1 & 0.8 & 0 & 0 & Yes \\
\hline NY4 & 0.1 & 0.9 & 1 & 0.5 & 1 & 4 & 0.8 & 0 & 0 & 0 & 0.6 & 1 & 1 & No \\
\hline BT4 & 0.1 & 0.8 & 1 & 0.2 & 0 & 3 & 0.3 & 1 & 0 & 0 & 0.9 & 0 & 0 & Yes \\
\hline HK5 & 0.3 & 1 & 1 & 0.2 & 0 & 7 & 0.2 & 1 & 0 & 1 & 1 & 0 & 0 & Yes \\
\hline Sp5 & 0.4 & 0.8 & 1 & 0.3 & 0 & 4 & 0.5 & 0 & 1 & 0 & 0.7 & 0 & 1 & Yes \\
\hline NY5 & 0.1 & 0.9 & 1 & 0.3 & 0 & 4 & 0.4 & 1 & 0 & 0 & 0.5 & 1 & 1 & No \\
\hline BT5 & 0.2 & 0.9 & 1 & 0.5 & 1 & 7 & 0.7 & 0 & 1 & 0 & 0.9 & 0 & 0 & No \\
\hline HK6 & 0.2 & 0.7 & 1 & 0.4 & 1 & 8 & 0.7 & 0 & 1 & 1 & 0.2 & 1 & 1 & Yes \\
\hline Sp6 & 0.3 & 1 & 1 & 0.3 & 0 & 4 & 0.3 & 1 & 0 & 0 & 0.8 & 0 & 0 & No \\
\hline NY6 & 0.3 & 1 & 1 & 0.4 & 0 & 5 & 0.2 & 1 & 1 & 1 & 0.9 & 0 & 0 & Yes \\
\hline BT6 & 0.3 & 0.8 & 1 & 0.2 & 0 & 4 & 0.7 & 1 & 0 & 0 & 1 & 0 & 0 & Yes \\
\hline HK7 & 0.4 & 0.9 & 0 & 0.2 & 1 & 6 & 0.1 & 1 & 0 & 0 & 0.8 & 0 & 1 & Yes \\
\hline Sp7 & 0.4 & 1 & 0 & 0.4 & 1 & 7 & 0.6 & 0 & 1 & 1 & 0.5 & 1 & 1 & Yes \\
\hline NY7 & 0.2 & 0.6 & 0 & 0.4 & 1 & 9 & 0.5 & 0 & 0 & 1 & 0.7 & 1 & 1 & Yes \\
\hline BT7 & 0.1 & 0.9 & 1 & 0.3 & 1 & 5 & 0.1 & 1 & 1 & 1 & 1 & 0 & 0 & Yes \\
\hline HK8 & 0.3 & 0.9 & 0 & 0.2 & 1 & 6 & 0.1 & 1 & 0 & 0 & 0.8 & 0 & 0 & Yes \\
\hline Sp8 & 0.4 & 0.9 & 0 & 0.3 & 1 & 8 & 0.6 & 1 & 0 & 1 & 0.5 & 1 & 1 & Yes \\
\hline NY8 & 0.3 & 0.7 & 1 & 0.4 & 0 & 9 & 0.6 & 0 & 0 & 1 & 0.6 & 1 & 1 & Yes \\
\hline BT8 & 0.1 & 0.8 & 1 & 0.3 & 1 & 6 & 0.1 & 1 & 1 & 1 & 1 & 1 & 0 & Yes \\
\hline HK9 & 0.3 & 0.9 & 1 & 0.3 & 1 & 6 & 0.4 & 1 & 0 & 1 & 0.8 & 1 & 1 & Yes \\
\hline Sp9 & 0.3 & 0.9 & 0 & 0.2 & 0 & 5 & 0.3 & 1 & 1 & 0 & 0.7 & 0 & 1 & Yes \\
\hline NY9 & 0.1 & 0.9 & 1 & 0.3 & 1 & 5 & 0.2 & 1 & 1 & 1 & 0.8 & 0 & 1 & Yes \\
\hline ВT9 & 0.2 & 0.8 & 0 & 0.5 & 1 & 6 & 0.5 & 0 & 0 & 1 & 0.3 & 1 & 1 & Yes \\
\hline HK10 & 0.3 & 1 & 0 & 0.4 & 0 & 6 & 0.4 & 1 & 0 & 0 & 0.6 & 1 & 1 & Yes \\
\hline Sp10 & 0.4 & 0.9 & 1 & 0.3 & 1 & 5 & 0.4 & 1 & 1 & 1 & 0.8 & 0 & 1 & Yes \\
\hline NY10 & 0.2 & 0.9 & 1 & 0.6 & 1 & 4 & 0.8 & 1 & 1 & 1 & 0.8 & 1 & 1 & Yes \\
\hline BT10 & 0.1 & 0.8 & 1 & 0.2 & 1 & 3 & 0.3 & 1 & 0 & 0 & 0.9 & 0 & 0 & Yes \\
\hline HK11 & 0.5 & 0.9 & 0 & 0.2 & 1 & 6 & 0.1 & 1 & 0 & 0 & 0.8 & 0 & 1 & No \\
\hline Sp11 & 0.4 & 0.9 & 0 & 0.4 & 1 & 7 & 0.6 & 1 & 1 & 1 & 0.5 & 1 & 1 & No \\
\hline NY11 & 0.3 & 0.7 & 1 & 0.5 & 0 & 9 & 0.5 & 0 & 0 & 1 & 0.7 & 1 & 1 & Yes \\
\hline BT11 & 0.1 & 0.9 & 1 & 0.3 & 1 & 7 & 0.2 & 1 & 0 & 0 & 0.5 & 0 & 1 & No \\
\hline
\end{tabular}

In the case when the data set $T$ contains $n$ classes, the Gini index is equal to:

$$
\operatorname{Gini}(T)=1-\sum_{i=1}^{n} p_{i}^{2}
$$

where $p_{\mathrm{i}}$ is the probability of class $i$ in $T$. In the problem under consideration, based on the CART algorithm, $T$ is divided into two parts $T_{1}$ and $T_{2}$ with the number of examples $N_{1}$ and $N_{2}$ in each part, respectively, then the division quality index is equal to:

$$
\operatorname{Gini}_{\text {split }}(T)=\frac{N_{1}}{N} \cdot \operatorname{Gini}\left(T_{1}\right)+\frac{N_{2}}{N} \cdot \operatorname{Gini}\left(T_{2}\right)
$$

where for

$$
\operatorname{Gini}(T) \rightarrow \min ,
$$

the result of division is achieved.

When constructing decision trees, let us assume that $N$ is the number of examples in the parent node, and $L, R$ is the number of examples in the left and right descendant, respec- 
tively, then $l_{i}$ and $r_{i}$ are the number of the $i$-th class examples in the left/right descendant. Then (13):

$$
\begin{aligned}
& \text { Gini }_{\text {split }}=\frac{L}{N} \cdot\left(1-\sum_{i=1}^{n}\left(\frac{l_{i}}{L}\right)^{2}\right)+ \\
& +\frac{R}{N} \cdot\left(1-\sum_{i=1}^{n}\left(\frac{r_{i}}{R}\right)^{2}\right) \rightarrow \min
\end{aligned}
$$

The best division is the one for which the value is maximum:

$$
\begin{aligned}
& \tilde{G}_{\text {split }}=\frac{1}{L} \cdot \sum_{i=1}^{n} l_{i}^{2}+ \\
& +\frac{1}{R} \cdot \sum_{i=1}^{n} r_{i}^{2} \rightarrow \max .
\end{aligned}
$$

The revealed features-identifiers affect the occurrence of critical situations, as confirmed by experimental data when using the NTPRO 5000 navigation simulator (Wärtsilä Corporation, Finland).

\section{3. Predicting likely critical situations}

In order to confirm the identified patterns, an automated predictive model was built based on data mining tech- nology, which made it possible to identify the likelihood of critical situations. The model was based on a database of navigation parameters in four locations, which allowed building a decision tree and determining the predicted effectiveness at its nodes. With regard to the processed data, based on typical navigation operations, it became possible to create a class of unified critical situations with a similar decision-making structure.

Based on the presented descriptions, we implement a simulation of the prediction of the probability of a critical situation according to the criterion Fr5 "Effectiveness of task performance by the navigator". Based on the CART algorithm and data mining module, we denote Fs1-Fs9 as dependent variables.

As a result of modeling, a tree was built in an automated way in which the main nodes of situation transformation were identified with respect to the parameters of the factors influencing the navigator's actions (Fig. 5). To build a decision-making system based on the data obtained, this is sufficient and does not require more complex data identification models [33].

When considering the obtained prediction results, the following dependences of the tree formation were determined, Table 4.

The resulting model was analyzed in terms of predic-

\begin{tabular}{|c|c|}
\hline No. & Development of navigation situation in relation to Fsi factors \\
\hline 1 & $\begin{array}{l}\text { The situation is based on the factor Fs "Determination of similarity completeness (flow rate, date and time of day, } \\
\text { vessel type)". Moreover, in situations where the similarity exceeds } 85 \% \mathrm{ID}=3 \text {, the probability of a successful outcome } \\
\text { is lower than in those where the similarity is lower. This is due to the fact that in situations without a clear similarity } \\
\mathrm{ID}=2 \text {, the navigator is more focused on the task, the area of attention and focus on elementary actions is increased }\end{array}$ \\
\hline 2 & $\begin{array}{l}\text { The situation goes to the node of the factor Fs } 6 \text { "Complexity by the } p \text {-adicity of the stage (ECDIS, ARPA, AIS, GPS } \\
\text { interfaces)". There is also a similar trend, indicating that if the complexity of the stage exceeds } 4.5 \text { units out of } 9 \\
\text { maximum ( } 50 \% \text { ) ID }=5 \text {, then the navigator is more aware of the navigation task being performed, which increases the } \\
\text { chances of success, in contrast to the reverse ID=4 }\end{array}$ \\
\hline 2.1 & $\begin{array}{l}\text { In the case of low Fs6 (less than } 50 \% \text { ) ID=4, the situation depends on the factor Fs9 "Synchronization with the team. } \\
\text { Coincidence of actions with the navigational watch". This factor can ensure safety if the synchronization is high and } \\
\text { other members of the watch perform the task at a high qualification level ID=7. Otherwise, the situation will inevitably } \\
\text { develop into critical ID=6, with an emergency outcome for the ergatic system and the vessel as a whole. In the case } \\
\text { of ID=6, it is necessary to resort to extreme emergency measures, switch to automatic vessel control using specialized } \\
\text { control modules }\end{array}$ \\
\hline 3 & $\begin{array}{c}\text { As can be seen in Fig. 3, the situation develops towards complication with respect to Fs } 6 \text { ID }=5 \text { and this leads to a con- } \\
\text { tinuous stressful situation regarding the next stage of vessel movement } \\
\text { in the location }\end{array}$ \\
\hline 3.1 & $\begin{array}{l}\text { Consider an option for this situation when the level of } p \text {-adicity of the stage increases significantly. It is clearly seen } \\
\text { that if the navigator is not helped at Fs } 6>6.5 \text { ID }=9 \text {, then the probabilities of a safe outcome and an accident become } \\
\text { equal. This development of events cannot satisfy either the vessel captain or the owner company }\end{array}$ \\
\hline 3.2 & $\begin{array}{c}\text { When the complexity level decreases, Fs } 6>6.5 \text { ID }=8 \text {, the probability of a successful outcome of the situation } \\
\text { is much higher }\end{array}$ \\
\hline 4 & $\begin{array}{c}\text { In each of the cases } 3.1 \text { and } 3.2 \text {, the situation becomes dependent on the factor Fs1 "Superposition of situations. Vessel } \\
\text { position relative to the ECDIS waypoint" with different parameters }\end{array}$ \\
\hline 4.1 & $\begin{array}{l}\text { In this case, the factor Fs } 1 \mathrm{ID}=13 \text { can stabilize the situation if the recognition of the area exceeds } 25 \% \text {. But the } \\
\text { probability is not so high as not to resort to hints for the navigator. If the situation recognition is low ID=12, then it is } \\
\text { necessary to switch to automatic vessel control }\end{array}$ \\
\hline 4.2 & $\begin{array}{l}\text { In the case of ID=11, with a high coincidence of the situation, the effect of "distraction" is also observed, affecting the } \\
\text { concentration of attention and focus on the situation, while a negative result is very likely, which requires preventive } \\
\text { measures, namely, strengthening the watch or replacing the navigator. At the same time, a moderate similarity will } \\
\text { stimulate the readiness of the navigator for the qualified performance of the task in ID=10 }\end{array}$ \\
\hline
\end{tabular}
tion reliability and costs relative to the dependent variable Fr5 (Fig. 6, $a, b$ ).

\section{Formation of simulation tree}




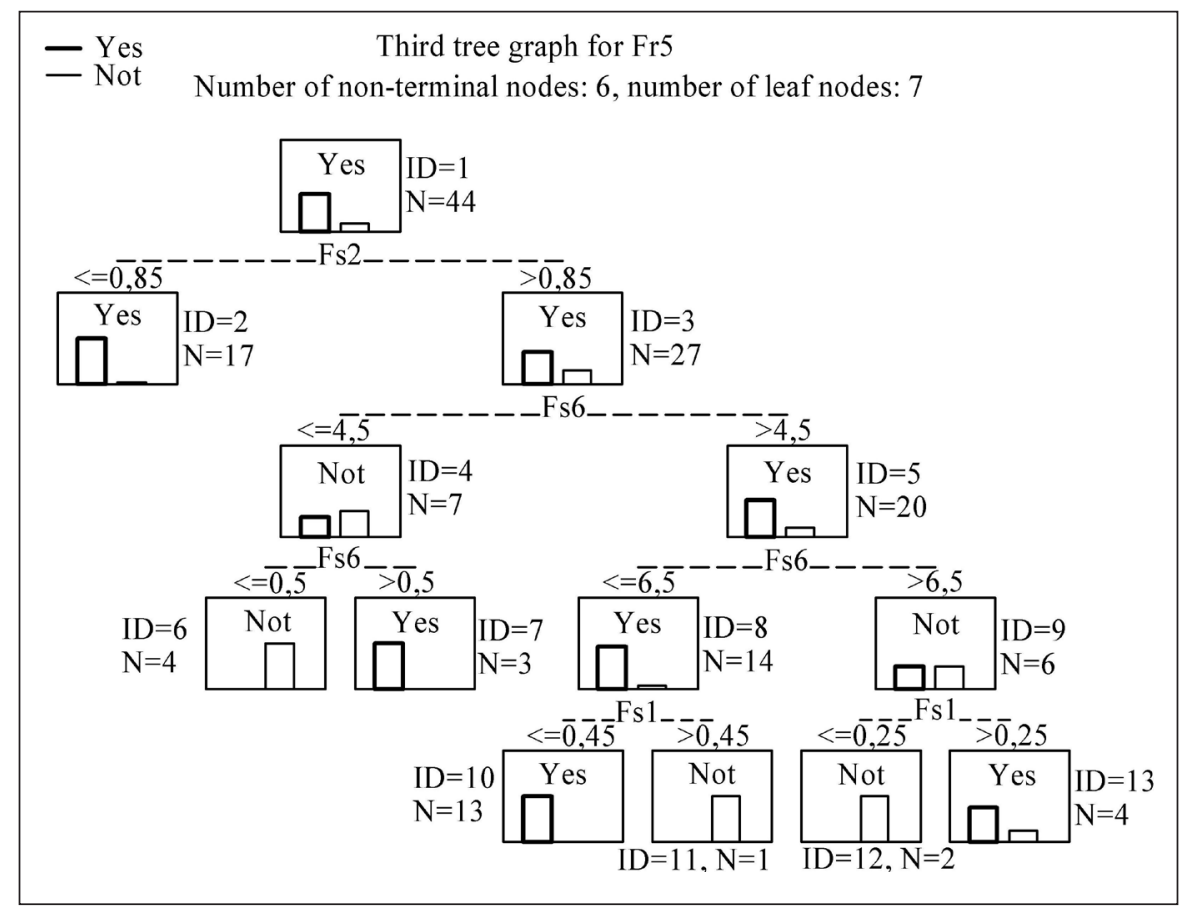

Fig. 5. Prediction tree of the situation under the influence of the navigator "human factor" on the ergatic vessel control system
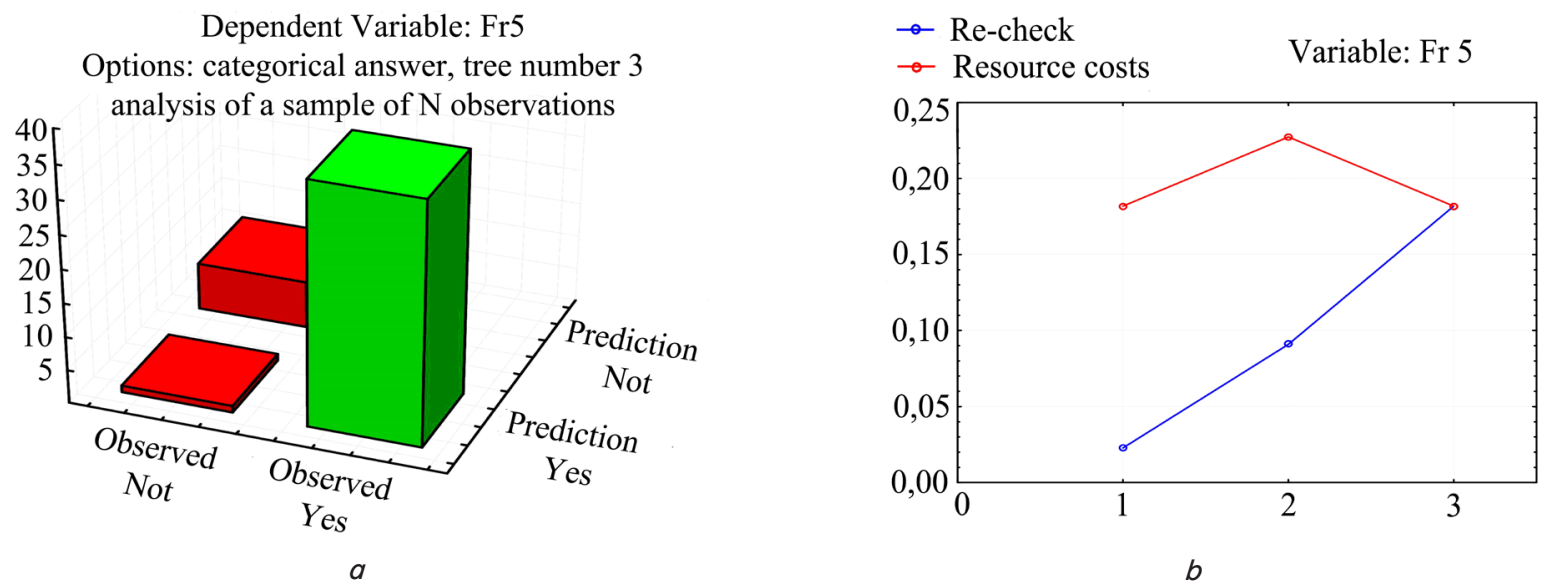

Fig. 6. Analysis of construction of a predictive model: $a$ - degree of prediction reliability; $b-$ analysis of tree construction costs

Further application of the developed predictive model for simulation involves the use of the NTPRO 5000 navigation simulator. Within the framework of this action, the task is to experimentally confirm the adequacy of the model for automated vessel control in critical situations.

\section{4. Emergency switching to automated vessel con-} trol mode

During the experiment, the system indexed dangerous situations, the example of passing the route (Fig. 7) shows that in two out of the four cases, it was necessary to significantly reduce speed to use thrusters and set a new course.

The use of the navigation safety control system significantly influenced the stabilization of the vessel trajec- tory in situations when the navigator could not make an adequate decision for the situation, and the captain did not have time to strengthen the watch ID=11, Fs1 $>0.45$ $\max \mathrm{V}$. At the same time, in contrast to switching to fully automated vessel control $[6,14,23]$, a combination of decision-making under conditions of optimal separation of control functions between the captain and the automated system was selected in this study.

In Fig. 8, it is clearly seen that switching to automatic control with a high degree of accuracy made it possible to neutralize the influence of the "human factor" of the navigator and prevent an accident.

The system monitored the data of devices and sensors to determine the point of switching to vessel control, and as a result, the constructed vessel trajectory turned out to be safe. 


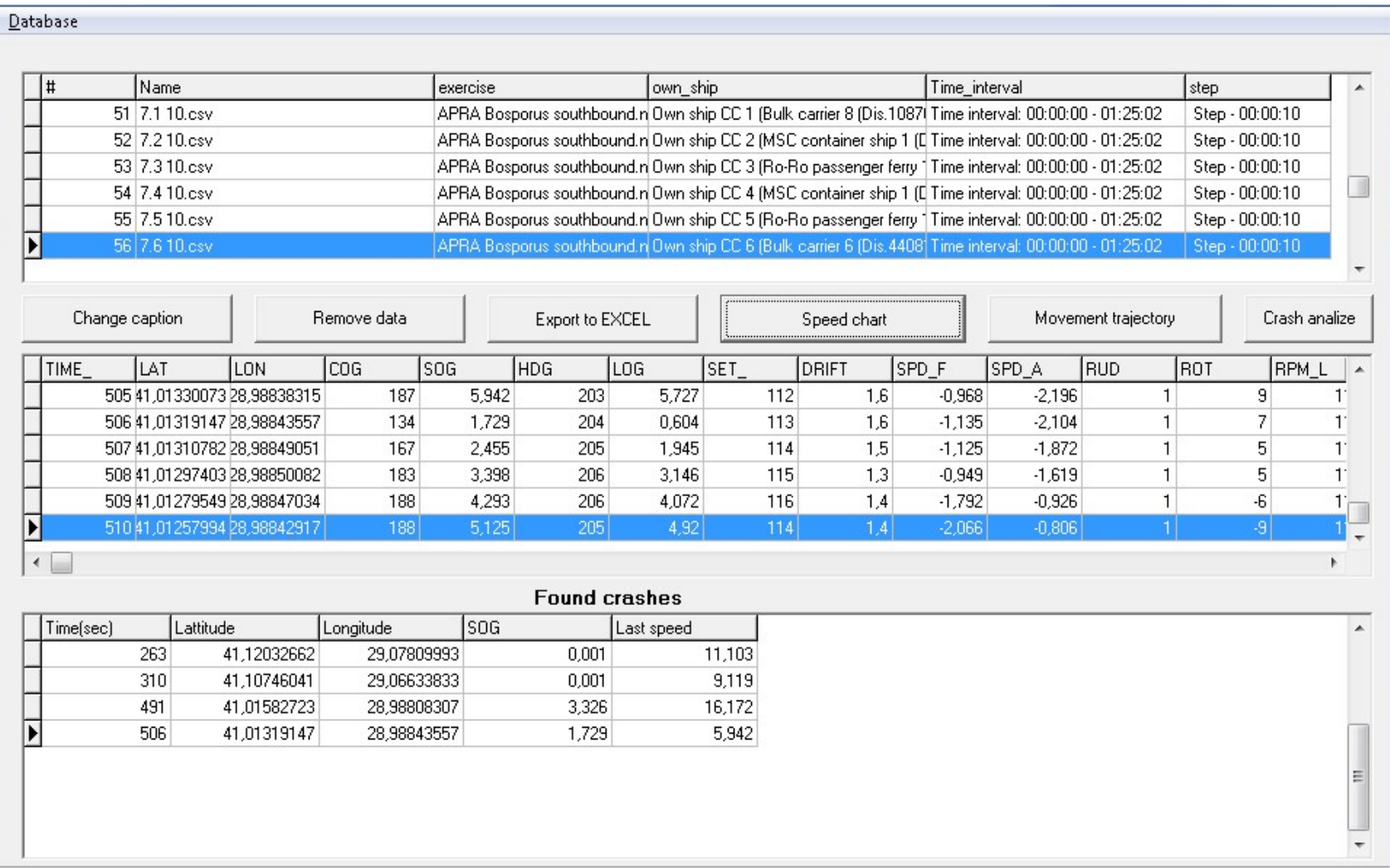

$a$
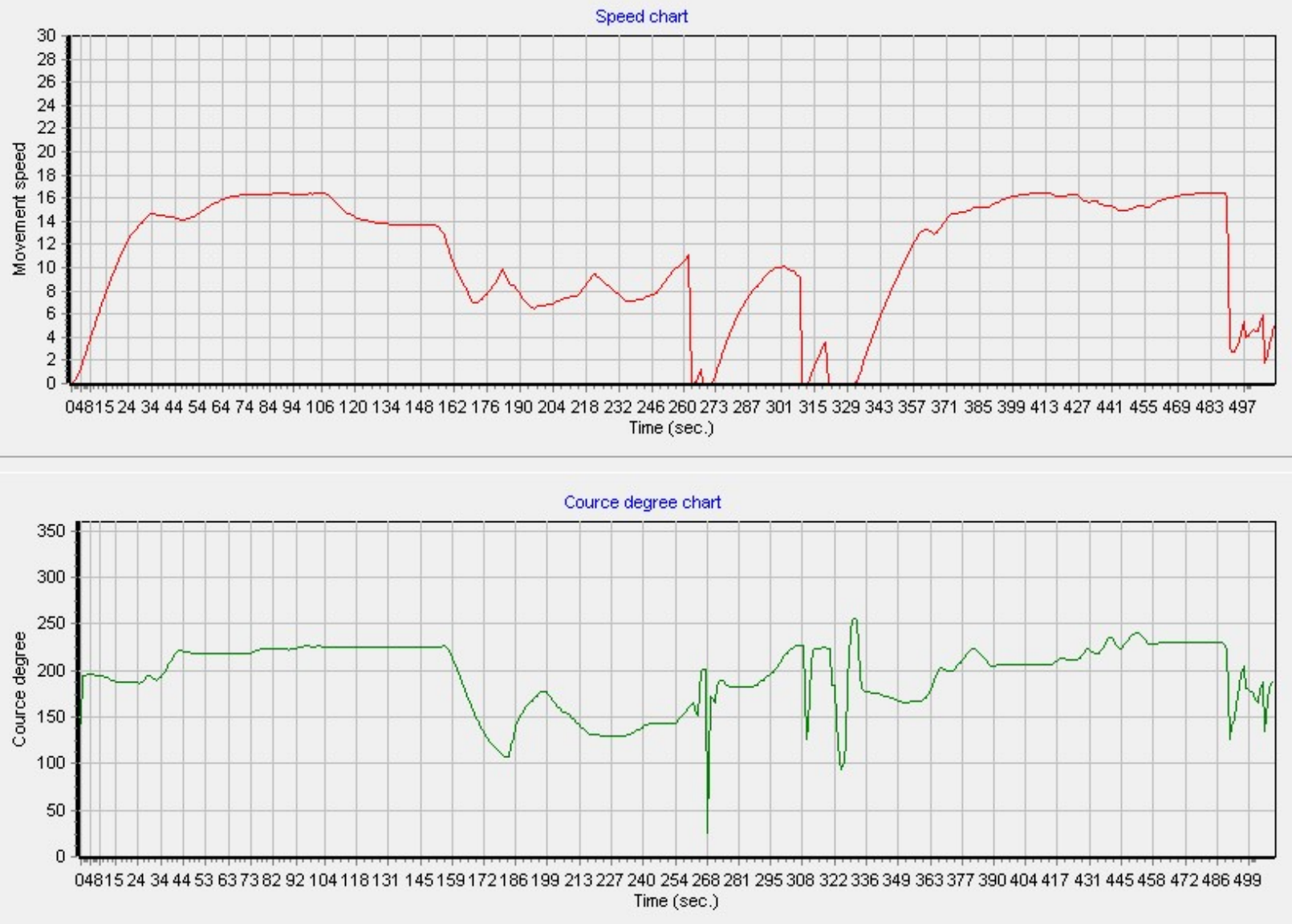

b

Fig. 7. System of identification of critical situations: $a$ - database of navigation parameters; $b$ - vessel movement indicators 




Fig. 8. Display of the vessel accident prevention maneuver

\section{Discussion of research results based on simulation}

The obtained results are explained by the fact that the diagram of the ergatic vessel control system (Fig. 3) made it possible to analyze both the navigator physiological parameters and vessel movement parameters, the distance to dangerous objects and dangerous navigation areas (Tables 1,2). By synchronizing the data streams in real time, within the framework of the proposed approach, the danger of the situation at each discrete moment in time with a step of 10 seconds was determined (Fig. 7).

A feature of the proposed approach is that the developed generalized model of the influence of the "human factor" on ergatic navigation systems made it possible to identify the emergence of a critical situation at early stages (Fig. 4). In turn, the construction of the prediction tree of the situation under the influence of the "human factor" (Fig. 5) determined the point of switching vessel control to automatic mode.

As a result of the experiments, the control system worked: in $11 \%$ of cases - switching to fully automatic control; in $18 \%$ - watch strengthening; in $25 \%$ - a hint to the navigator. Thus, the degree of control system coverage was about $41 \%$ of the cases. The tasks were also classified based on the coincidence of prediction models, which made it possible to significantly expand the database of the vessel control system for critical situations in the future.

As limitations of the developed system, it is possible to indicate an incomplete range of navigator physiological parameters, which is rather difficult to organize in dynamic working conditions on the captain's bridge. There is also the lack of qualified psychologists [34], which does not allow for a deeper analysis to identify the causes of a stressful situation in the navigational watch.

One of the difficult aspects of the study is to determine the boundaries between the sets of data that produce the adoption of a particular management decision. This issue was resolved with the help of expert assessments, however, in the future development of this scientific direction with the generalization of a data larger array, an attempt will be made to create a completely independent artificial intelligent system.

The development of this area involves the synthesis of scientific results in related areas of knowledge, such as formal systems of stochastic, fuzzy uncertainty, modern psychology and automated control systems. In this case, an important element will be a model experiment in the conditions of navigation in many locations of the world ocean. Direct collection of data from onboard systems will enhance the effectiveness of scientific research and allow unifying and generalizing the results. An important stage in the development of this direction is to accurately determine the criticality of the situation. So, for example, in less critical situations, the control system sends a signal to the vessel master (coastal services), as a result of which a decision is made to replace this navigator and/or to strengthen the watch. In situations with an even lower risk probability, the navigator receives signals warning of the complication of the navigation situation.

\section{Conclusions}

1. The peculiarity of the developed diagram of the ergatic vessel control system for critical situations is that the "Navigation situation monitoring system" module has been introduced, which makes it possible to identify critical situations by indirect features. The diagram provides for the differentiation of control actions in critical situations by means of modules: alarm system, automatic control system and switching to automatic control. Information links between the diagram modules made it possible to determine the most significant factors affecting the navigation safety control processes.

2. The uniqueness of the developed generalized model of the identification process and the influence of the navigator "human factor" on the ergatic vessel control system lies in analyzing the subject's influence on navigation safety. The proposed logical-formal approaches to extracting data with a complex structure made it possible to synthesize external influences, navigator's perception of the situation, prediction of the probabilities of disasters and the final performance of the task. In this case, the key parameters of the factors were the temporal indicators of atomic reactions, psychophysiological state, the complexity of situation perception, criterion of distinguishability of situations in relation to the navigator's experience. The presented feature of the model made it possible to synthesize data in the form of factors that determine the situation and factors affecting the occurrence of risk, as well as correlate them with the results of modeling on the navigation simulator. Data synthesis directed the research towards the use of data mining automated simulation tools.

3. The feasibility of the developed predictive model of probable critical situations by data mining means made it possible to obtain a full range of probabilities of ecritical situations in relation to the processed data array. Probabilistic trees constructed in an automated way made it possible, on the one hand, to determine the most significant factors relative to the selected set of typical situations, and on the other hand, to generate the response of the navigation safety control system at each node of the tree. This allowed determining the dynamics of navigation situations and identifying the most dangerous branches of the model, depending on the parameter ranges of the influencing factors.

4. Automated analysis of experimental data from the Navi Trainer 5000 navigation simulator made it possible to 
determine the physical parameters of vessel movement and correlate them with the probability of critical situations. As a result, a module for emergency switching of vessel control to the automatic maneuvering mode was developed to prevent accidents. Using the maneuvering characteristics of the vessel at a given speed, the position of the rudder blade and vessel's circulation capabilities made it possible to determine the boundary point on the trajectory when switching to automatic control mode. At the moment of extreme danger, the mode of the full reverse of vessel movement is provided.

\section{Acknowledgments}

The team of authors is grateful to the management of the Kherson State Maritime Academy (Ukraine) for the opportunity to conduct research on the basis of the research laboratory "Development of decision support systems, ergatic and automated vessel control systems" using the certified Navi Trainer 5000 navigation simulator. The study was carried out within the framework of the research topic No. 0121U109680 "Development of latest models and software for automated control systems for civil and special-purpose marine vessels".

\section{References}

1. Andersson, P., Ivehammar, P. (2016). Cost Benefit Analysis of Dynamic Route Planning at Sea. Transportation Research Procedia, 14, 193-202. doi: https://doi.org/10.1016/j.trpro.2016.05.055

2. Benyon, D. (2006). Information Space. Encyclopedia of Human Computer Interaction, 344-347. doi: https://doi.org/10.4018/ 978-1-59140-562-7.ch053

3. Chen, L., Xu, X., Zhang, P., Zhang, X. (2018). Analysis on Port and Maritime Transport System Researches. Journal of Advanced Transportation, 2018, 1-20. doi: https://doi.org/10.1155/2018/6471625

4. Romero, C., Mejia, M. (Eds.) (2020). Maritime Transportation and Ocean Policies. WMU. doi: https://doi.org/10.21677/ srca201909

5. Pleskacz, K., Uriasz, J. (2012). Understanding of Navigational Information Systems. Annual of Navigation, 19 (1), $121-132$. doi: https://doi.org/10.2478/v10367-012-0010-z

6. Valdez Banda, O. A., Kujala, P., Hirdaris, S. (2021). Virtual special Issue: Autonomous vessels safety. Safety Science, 136, 105144. doi: https://doi.org/10.1016/j.ssci.2020.105144

7. Pinakpani, P., Polisetty, A., Bhaskar, G., Sunil, H., Mohan, B., Deepthi, D., Sidhireddy, A. (2020). An Algorithmic Approach for Maritime Transportation. International Journal of Advanced Computer Science and Applications, 11 (2). doi: https:// doi.org/10.14569/ijacsa.2020.0110296

8. Bazaras, D., Palšaitis, R., Petraška, A., Zvaigzne, A. (2017). Criteria System of Emergency Situations Risks Assessment in the Baltic Sea Ports. Transport and Telecommunication Journal, 18 (4), 275-281. doi: https://doi.org/10.1515/ttj-2017-0024

9. Smolarek, L. (2010). Dimensioning the Navigational Safety in Maritime Transport. Journal of Konbin, 14-15 (2010), 271-280. doi: https://doi.org/10.2478/v10040-008-0184-6

10. Hareide, O. S., Ostnes, R. (2017). Scan Pattern for the Maritime Navigator. TransNav, the International Journal on Marine Navigation and Safety of Sea Transportation, 11 (1), 39-47. doi: https://doi.org/10.12716/1001.11.01.03

11. Devlin, K. (2006). Situation theory and situation semantics. Handbook of the History of Logic, 601-664. doi: https://doi.org/ 10.1016/s1874-5857(06)80034-8

12. Smirnova, O. (2018). Situation Awareness for Navigation Safety Control. TransNav, the International Journal on Marine Navigation and Safety of Sea Transportation, 12 (2), 383-388. doi: https://doi.org/10.12716/1001.12.02.20

13. Cherniavskyi, V., Popova, H., Sherman, M., Voloshynov, S., Yurzhenko, A. (2020). Mixed reality technologies as a tool to form professional competency of seatransport professionals. CEUR Workshop Proceedings, 2740,217-231. Availableat:http://ceur-ws.org/ Vol-2740/20200217.pdf

14. Zhou, X. Y., Liu, Z. J., Wu, Z. L., Wang, F. W. (2019). Quantitative Processing of Situation Awareness for Autonomous Ships Navigation. TransNav, the International Journal on Marine Navigation and Safety of Sea Transportation, 13 (1), 25-31. doi: https:// doi.org/10.12716/1001.13.01.01

15. Benz, T. M. (2019). Multi-modal user interfaces in teleoperation. Dissertation, Rheinisch-Westfälische Technische Hochschule Aachen. doi: http://dx.doi.org/10.18154/RWTH-2019-03285

16. Psarros, G. A. (2015). Bayesian Perspective on the Deck Officer's Situation Awareness to Navigation Accidents. Procedia Manufacturing, 3, 2341-2348. doi: https://doi.org/10.1016/j.promfg.2015.07.381

17. Popovych, I., Blynova, O., Kuzikova, S., Shcherbak, T., Lappo, V., Bilous, R. (2021). Empirical research of vitality of representatives of parachuting and yoga practice: a comparative analysis. Journal of Physical Education and Sport, 21 (1), 218-226. doi: https:// doi.org/10.7752/jpes.2021.01029

18. Popova, H., Yurzhenko, A. (2019). Competency framework as an instrument to assess professional competency of future seafarers. CEUR Workshop Proceedings, 2387, 409-413. Available at: http://ceur-ws.org/Vol-2387/20190409.pdf

19. Popovych, I., Blynova, O., Nosov, P., Zinchenko, S., Kononenko, O. (2021). Psychological factors of competitiveness of the women's youth handball team. Journal of Physical Education and Sport, 21 (1), 227-235. doi: https://doi.org/10.7752/jpes.2021.01030

20. Torskiy, V., Topalov, V. P., Chesnokova, M. (2016). Conceptual Grounds of Navigation Safety. TransNav, the International Journal on Marine Navigation and Safety of Sea Transportation, 10 (1), 79-82. doi: https://doi.org/10.12716/1001.10.01.08 
21. Kim, D.-Y., Jo, D.-W., Yi, M.-R., Park, G.-K. (2010). Intelligent Navigation Safety Information System based on Information-Fusion Technology. Journal of Korean Institute of Intelligent Systems, 20 (2), 226-233. doi: https://doi.org/10.5391/jkiis.2010.20.2.226

22. Gartenberg, D., Breslow, L., McCurry, J. M., Trafton, J. G. (2013). Situation Awareness Recovery. Human Factors: The Journal of the Human Factors and Ergonomics Society, 56 (4), 710-727. doi: https://doi.org/10.1177/0018720813506223

23. Zinchenko, S., Tovstokoryi, O., Nosov, P., Popovych, I., Kobets, V., Abramov, G. (2020). Mathematical support of the vessel information and risk control systems. CEUR Workshop Proceedings, 2805, 335-354. Available at: http://ceur-ws.org/Vol-2805/ paper25.pdf

24. Nosov, P., Zinchenko, S., Popovych, I. S., Safonov, M., Palamarchuk, I., Blakh, V. (2020). Decision support during the vessel control at the time of negative manifestation of human factor. CEUR Workshop Proceedings, 2608, 12-26. Available at: http://ceur-ws.org/ Vol-2608/paper2.pdf

25. Solovey, O., Ben, A., Dudchenko, S., Nosov, P. (2020). Development of control model for loading operations on heavy lift vessels based on inverse algorithm. Eastern-European Journal of Enterprise Technologies, 5 (2 (107)), 48-56. doi: https://doi.org/ $10.15587 / 1729-4061.2020 .214856$

26. Volkov, Y. (2019). A study of decomposition of a group of ships for preliminary forecasting of dangerous approaching. EasternEuropean Journal of Enterprise Technologies, 3 (3 (99)), 6-12. doi: https://doi.org/10.15587/1729-4061.2019.165684

27. Nosov, P., Ben, A., Zinchenko, S., Popovych, I., Mateichuk, V., Nosova, H. (2020). Formal approaches to identify cadet fatigue factors by means of marine navigation simulators. CEUR Workshop Proceedings, 2732, 823-838. Available at: http://ceur-ws.org/ Vol-2732/20200823.pdf

28. Prokopchuk, Y. A. (2017). Sketch of the Formal Theory of Creativity. Dnepr: PSACEA Press, 452. Available at: https:// www.researchgate.net/publication/319331415_Sketch_of_the_formal_theory_of_creativity

29. Marasanov, V., Sharko, A., Sharko, A., Stepanchikov, D. (2019). Modeling of Energy Spectrum of Acoustic-emission Signals in Dynamic Deformation Processes of Medium with Microstructure. 2019 IEEE 39th International Conference on Electronics and Nanotechnology (ELNANO). doi: https://doi.org/10.1109/elnano.2019.8783809

30. Babichev, S., Sharko, O., Sharko, A., Mikhalyov, O. (2019). Soft Filtering of Acoustic Emission Signals Based on the Complex Use of Huang Transform and Wavelet Analysis. Lecture Notes in Computational Intelligence and Decision Making, 3-19. doi: https:// doi.org/10.1007/978-3-030-26474-1_1

31. Khrennikov, A. Yu., Nilson, M. (2004). Theory of P-Adic Valued Probability. P-adic Deterministic and Random Dynamics, 229-254. doi: https://doi.org/10.1007/978-1-4020-2660-7_13

32. Breiman, L., Friedman, J. H., Olshen, R. A., Stone, C. J. (1984). Classification and Regression Trees. Wadsworth, Belmont, CA.

33. Babichev, S., Durnyak, B., Sharko, O., Sharko, A. (2020). Technique of Metals Strength Properties Diagnostics Based on the Complex Use of Fuzzy Inference System and Hybrid Neural Network. Data Stream Mining \& Processing, 114-126. doi: https:// doi.org/10.1007/978-3-030-61656-4_7

34. Popovych, I., Blynova, O., Halian, I., Savchuk, O. (2020). Self-efficacy of future athletes with different levels of psychological safety. Journal of Physical Education and Sport, 20 (5), 2718-2724. doi: https://doi.org/10.7752/jpes.2020.05370 